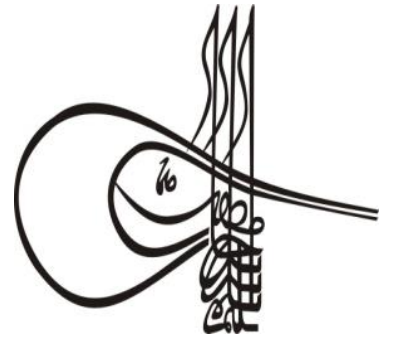

Received/Geliș: 16.04 .2019

\section{Turkígh Studies}

Social Sciences

Volume 14 Issue 3, 2019, p. 739-754

DOI: 10.29228/TurkishStudies. 22916

ISSN: 2667-5617

Skopje/MACEDONIA-Ankara/TURKEY

Research Article / Araștırma Makalesi

Article Info/Makale Bilgisi

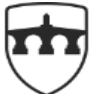

INTERNATIONAL BALKAN UNIVERSITY

EXCELLENCE FOR THE FUTURE IBU.EDU.MK

Go Report Dates/Rapor Tarihleri: Referee 1 (29.04.2019)-Referee 2 (03.05.2019)- Referee 3 (06.05.2019)

This article was checked by iThenticate.

\title{
SOYUT SANATIN ESRARENGİZ ÖNCÜSÜ: HİLMA AF KLINTT
}

\author{
Tuba KINAY GÖR*
}

\begin{abstract}
öz
Bu çalışmada, ülkemizde henüz adı pek duyulmamış ancak dünya sanat tarihinde çoktan hak ettiği yeri edinmiş olan İsveçli bir sanatçı tanıtılmaktadır; Hilma Af Klint. Bu sanatçının sanat tarihindeki yeri ve önemi konusuna odaklanılırken, "Soyut sanat nedir? İlk temsilcisi kimdir? Hangi dönemde karşımıza çıkar?” vb. sorular, konunun aydınlanmasına 1şık tutar. Otomatizm kavramı araştırılırken yerli bir makalede adı geçen Klint ilgi çekici bulunmuş, araştırılmasının ve paylaşılmasının günümüz sanat dünyası açısından faydalı olacağına inanılarak, çoğunluğu yabancı kaynaklı tez, makale, biyografi kitapları ve bazı sanat galerisi ve internet sitelerinden çeviriler yapılarak, alıntılama yoluyla betimsel bir analiz yöntemi kullanılmıştır. Bu analiz sonucunda, Klint’in ilahi bir güçten mesajlar aldığı ve bunu otomatik yazı ile Sürrealistlerden önce deneyimlediği, 1906'da tinselciliğe dayalı olarak yaptığı devasa boyuttaki eserleriyle Kandinsky, Mondrian ve Malevich’ten çok daha önce soyut resimler yapmış olduğu görülmüştür.

Günümüz sanat tarihi açısından bir dönüm noktası olacak olan bu yayın, sadece sanatın hareketli akışkanlığını ortaya koymakla kalmayacak, aynı zamanda yirminci yüzyılda soyut sanatın anlatımına da meydan okuyacak türde bir araştırmadır. Bu çalışmada önce sanat tarihi bakımından soyut sanat kavramı ele alınırken, ardından Hilma af Klint'in kısaca hayatına, sanat eğitimine ve sanatsal üretimlerine değinilerek, sanatçının kendi not defterinden de faydalanılarak yaptığı bazı resimler, içinde yaşadığı dönem açısından bu resimlerin önemi ve farklıları vurgulanmıştır. Bu çalışma ile ilk soyut resim sanatçısı olan Hilma Af Klint'i ülkemize tanitarak, soyut sanat anlamında önemli bir eksikliğin giderilmesi amaçlanmaktadır.
\end{abstract}

Anahtar Kelimeler: Soyut Sanat, Kandinsky, Hilma Af Klint, tinsellik, otomatizm 


\title{
THE LEADER OF ABSTRACT ART: HILMA AF KLINNT
}

\begin{abstract}
In this study, we are introduced to a Swedish artist whose name is not yet heard in our country, but who has already earned the deserved place in world art history; Hilma Af Klint. While focusing on the place and importance of this artist in art history, "What is abstract art? Who is the first representative? In what period?" questions light on the subject. While searching the concept of automatism, Klint mentioned in a local article was found to be interesting, and it was believed that the research and sharing would be beneficial for today's art world. A descriptive analysis method was used by quoting the essays, articles, biography books and some art galleries and web sites. As a result of this analysis, it was seen that Klint received messages from a divine power and experienced this with automatic writing before the Surrealists and made abstract paintings long before Kandinsky, Mondrian and Malevich with his enormous works based on spirituality in 1906.

This publication, which will be a turning point in today's art history, is not only a study of the moving fluidity of art, but also a challenge to the expression of abstract art in the twentieth century. In this study, the concept of abstract art is firstly discussed in terms of art history, then the life, art education and artistic productions of Hilma af Klint are briefly mentioned and some of the paintings that the artist makes by using her own notebook and the importance and differences of these paintings in terms of the period in which she lived are emphasized. The aim of this study is to introduce Hilma Af Klint, the first abstract artist, to our country and to eliminate a significant lack of abstract art.
\end{abstract}

\section{STRUCTURED ABSTRACT}

In this study, we are introduced to a Swedish artist whose name is not yet heard in our country, but who has already earned the deserved place in world art history; Hilma Af Klint. While focusing on the place and importance of this artist in art history, she said, yeri What is abstract art? Who is the first representative? In what period? questions shed light on the subject. While searching the concept of automatism, Klint mentioned in a local article was found to be interesting, and it was believed that the research and sharing would be beneficial for today's art world. A descriptive analysis method was used by quoting the essays, articles, biography books and some art galleries and web sites. . As a result of this analysis, it was seen that Klint received messages from a divine power and he experienced it before the Surrealists with automatic writing, and in 1906, with her enormous paintings based on spirituality, it was found that he made the first abstract painting five years before Wassily Kandinsky. Based on this, the pioneer of the first abstract painting proved to be Hilma Af Klint.

Within the scope of the literature review conducted in YÖK library with the preliminary acceptance that constitutes an important data in academic-based researches, there are many academic studies related to abstract art as well as articles in both electronic and printed sources, and 
also in Turkish and other languages in connection with the concept of abstract painting. the publication of the book was also observed. When evaluating these resources, which are related to the topic of the pioneers of abstract art up to the present from the past in Turkey, it expressed as Wassily Kandinsky, but if foreign sources after 1987 is claimed to have produced the work with the first abstract paintings understanding of a different artist in his place; Swedish painter Hilde Af Klint (Peyton-Jones J., Obrist H.; 2016, Birnbaum D., Fer B., Joseph B., Lomas D., Obrist H. U.; 2017, Bauduin T., Birnbaum D., Fer B., Greene V., Horowitz D. M., Kollnitz A., Molesworth H., Voss J.; 2018...vb.).

It is known that Wassily Kandinsky, who was accepted as the pioneer of abstract art, made his first abstract painting in 1911. After the researches and investigations, however, five years ago (1906), the first abstract painting by a woman artist named Hilma Af Klint was made; the fact that her works could come to light during the year was encountered (Sarığlu S., 2018; Birnbaum D., Fer B., Joseph B., Lomas D., Obrist H. U.; 2017). Therefore, the abstractions of Klint are based on before Kandinsky, known for inventing the abstract painting (Midavaine B.;2015).

The artist has produced works inspired by a series of spiritual research and experimental movements such as spirituality, theology, and then anthropology. In the beginning of 1906, he designed large-scale canvases filled with grids, circles, spirals and similar forms, sometimes diagrammatic and sometimes biomorphic. It is another amazing fact that Klint, who had seen monochrome watercolors in 1916, made automatic drawings much earlier than the Surrealists (Peyton-Jones J., Obrist H., 2016). Before the Surrealists, they had created a group called ve The Five yyla that would be given more detailed information about the four women artists who organized sessions and experimented with automatic writing and drawing. Good and bad in Klint's works, indicating that his hand is the only spiritual power; male and female; It is seen that it draws the path to harmony between material and spiritual worlds such as religion and science.

Although there is no academic finding on this issue in domestic sources, it has been seen that this artist is included in personal and news articles on several websites. In one of them, "Hilma af Klint, one of the pioneers of the twentieth century abstract painting, is remembered in the Hamburg Bahnhof Museum in Berlin, with an exhibition titled af The Pioneer of Abstract inden, an artist's innovative and mystical works..." (Euronews; 28/06/2013); in the form of a news report, on another personal website, "Today I met the painter Hilma Af Klint, thanks to my friend Morgan. I was evaluating the project presentations on the occasion of the final period, when Morgan reflected Af Klint's paintings on the wall with the projector for her presentation. I fell in love with Hilma before I knew who had any more of her" (Sever, H. L. http://www.5harfliler.com, 09.12.2013) in the article the author explanes, the eye-catching orange and purple in the tables, talking about his admiration of abstraction technique. And also "After all, the first abstract painting was drawn by Af Klint in 1906, not Kandinsky in 1911" she emphasized. In addition to this, abstracts from the official website of wikiart (https://www.bilgiustam.com/hilma-af-klint-hayati-ve-eserleri/), although some opinions about the artist are shared in a commentary site, 
it is surprising that there is no artistic and scientific data about this mysterious vanguard of art. Thereupon, foreign thesis studies, books about the artist, artist's own notebooks, exhibition catalogs, newspaper news, videos etc. It was observed that there were much more material than expected.

As a result of the researches, although the abstract paintings of Hilma Af Klint from the beginning of the 20th century were not presented to the public until 1987, it was seen that Kandinsky, Mondrian and Malevich had been done before the first abstract paintings (Midavaine 2015, http://hilmaafklint.louisiana.dk, https://www.theartstory.org ... etc.). This publication, which will be a turning point in terms of contemporary art history, is not only to reveal the fluidity of art but also to challenge the expression of abstract art in the twentieth century. In this study, firstly, the concept of abstract art in the history of art is discussed, followed by Hilma af Klint, briefly referring to his life, art education and artistic production, some of the paintings that the artist makes from his own notebook and emphasizes the importance and differences of these paintings in terms of the period in which he lived. by introducing Hilma Af Klint, which is an abstract painting artist, to our country, it is aimed to eliminate an important deficiency in abstract art.

Throughout her art life, Hilma af Klint worked with insufficient knowledge and knowledge about the avant-garde movement in Europe. Klint has made over 1000 abstract paintings, as a theme, depicting the relationship between humanity and the cosmos, the development or evolution of humanity, the contradictions of men and women, celestial and underground, good and bad, peace and war. In these paintings, the artist combines geometric shapes and symbols with ornaments. Through the multifaceted images he uses in his paintings, the artist tries to give insights into the different dimensions of the micro cosm and the macro cosmos's existence that reflect each other. It can be said that the artist, who attracted attention with his huge-sized canvases, mostly directed to mystical subjects, fed on spirituality and based on automatism in a highly effective painting language. Such as Wassily Kandinsky, as Piet Mondrian and Kazimir Malevich, who had previously been the protagonists of abstract art, Klint was influenced by contemporary spiritual movements such as spirituality, the theosophism, and later anthropology, but while others were not a divine guide, the works of Hilma af Klint were spiritual. we see that it is based on the guide.

Artist has collected his sketches, thoughts and his spiritual experiences in 125 diaries. In these diaries, she not only records what is in the mind of his mind, but she also states that she is charged with describing the relationship between humanity and the cosmos and depicting the journey of man to a higher understanding. In a section of the journals, 20 years after her death, there is information about how the works should be presented in an atmosphere and in which order. It is ironic that this period, which is planned to be revealed, corresponds to the 1960s when abstract painting was brought to the peak in the history of modern art. In spite of her will, his works were presented to the public only 40 years later. At the moment, it is under the protection of a foundation opened on behalf of these works. 
After all, it would not be wrong to say that the pioneer of abstract painting is not Kandinsky but Hilma af Klint. Because Klint has presented philosophical ideas and spiritual concepts in the physical forms on the massive canvases, in order to see and reflect upon the humanity by pointing the asa Invisible els with the help of the dynamic link she established before Kandinsky. Many congresses have been held about the artist, books have been written and academic studies have been done. This clearly shows how powerful she is.

Keywords: Absract Art, Kandinsky, Hilma Af Klint, spiritualism, automatism

\section{Giriş}

Akademik tabanlı araştırmalarda önemli bir veri teşkil ettiği ön kabulüyle YÖK kütüphanesinde yapılan kaynak taraması kapsamında, soyut sanata ilişkin pek çok akademik çalışmaya rastlandığı gibi, gerek elektronik gerekse basılı kaynaklarda yer alan makalelerin olduğu, yine soyut resim anlayışı ile bağlantılı olarak Türkçe ve diğer dillerde pek çok kitabın yayımlandığı da gözlemlenmiştir. Konuyla ilgili olan bu kaynaklar değerlendirildiğinde, Türkiye'de geçmişten günümüze kadar soyut sanatın öncüsünün Wassily Kandinsky olarak ifade edildiği, ancak yabancı kaynaklarda ise 1987'den sonra onun yerine bambaşka bir sanatçının ilk soyut resim anlayışıyla çalışmalar üretmiş olduğu iddia edilmektedir; İsveçli ressam Hilde Af Klint (Peyton-Jones J., Obrist H.; 2016, Birnbaum D., Fer B., Joseph B., Lomas D., Obrist H. U.; 2017, Bauduin T., Birnbaum D., Fer B., Greene V., Horowitz D. M., Kollnitz A., Molesworth H., Voss J.; 2018...vb.).

Soyut sanatın öncüsü olarak kabul gören Wassily Kandinsky'nin ilk soyut resmini 1911'de yapıldığı bilinmektedir. Yapılan araştırma ve incelemelerin sonrasında, Ancak ondan beş sene önce (1906) Hilma Af Klint adlı bir kadın sanatçı tarafından ilk soyut resmin yapılmış olduğu, 1000'in üzerinde soyut resim yapan sanatçının yaşamış olduğu ve ölümünden 20 yıl sonra eserlerinin paylaşılmasına izin verdiği halde ancak 40 yıl sonra eserlerinin gün yüzüne çıkabildiği gerçeğiyle karşılaşılmıştır (Sarığlu S., 2018; Birnbaum D., Fer B., Joseph B., Lomas D., Obrist H. U.; 2017). Dolayısıyla Klint'in soyutlamaları, soyut resmi icat etmekle tanınan Kandinsky'den öncesine dayanmaktadır (Midavaine B.;2015).

Söz konusu sanatçı, ruhsallık, Teosofi ve daha sonra Antropoloji gibi zamanındaki bir dizi ruhsal araştırma ve deneysel akımdan ilham alarak işler üretmiştir. Bu sanatçı, 1906'nın başlarında, 1zgaralar, daireler, spiraller ve benzeri formlarla dolu büyük ölçekli tuvaller tasarlamış, bazen diyagramatik, bazen de biyomorfik çalışmıştır. 1916'da monokrom suluboyalar da yaptığı görülen Klint'in Sürrealistler'den çok daha önce otomatik çizimler yaptığı da şaşırtıcı başka bir gerçekliktir (Peyton-Jones J., Obrist H., 2016). Sürrealistlerden önce, seanslar düzenleyen ve otomatik yazma ve çizme denemeleri yapan dört kadın sanatçıyla birlikte daha sonra detaylıca hakkında bilgi verilecek olunan "The Five" adlı bir grup da kurmuşlardı. Elini yönlendirenin sadece manevi güçler olduğunu belirten Klint'in eserlerinde iyi ve kötü; erkek ve kadın; din ve bilim gibi maddi ve manevi dünyalar arasındaki uyuma giden yolu çizdiği görülmektedir.

Yerli kaynaklarda akademik anlamda bu konuya ilişkin hiçbir bulguyla karşılaşılmamış olmasına rağmen birkaç internet sitesinde kişisel ve haber nitelikli yazılarda bu sanatçıya yer verildiği görülmüştür. Bunlardan bir tanesinde, "20. yüzy1l soyut resminin öncülerinden Hilma af Klint, Berlin'de yer alan Hamburg Bahnhof Müzesi'nde sanatçının yenilikçi ve mistik eserlerinden oluşan "Soyutluğun Öncüsü” adlı sergiyle anılıyor... (Euronews; 28/06/2013); şeklinde bir habere ulaş1lırken, bir başka kişisel internet sitesinde, "Bu gün kadın ressam Hilma af Klint ile gülüşü saçının dalgası kadar güzel olan arkadaşım Morgan sayesinde tanıştım. Final dönemi vesilesiyle proje sunumların 
değerlendiriyordum Morgan sunumu için af Klint'in tablolarını projektörle duvara yansıttığında. Hilma 'nın daha kimin nesi olduğunu ögrenemeden aşık olmuştum. İlk görüşte derler ya öyle... " (Sever, H. L. http://www.5harfliler.com, 09.12.2013) şeklinde başlayan makalede yazar, tablolardaki göz alıcı turuncu ve morlardan, soyutlama tekniğine duyduğu hayranlıktan bahsederek; "...Neticede ilk soyut resmi 1911'de Kandinsky değil 1906'da af Klint çizmiştir." diye de vurguda bulunmuştur. Bunların yanı sıra, wikiart resmi sitesinden dilimize çevirerek aktaran (https://www.bilgiustam.com/hilma-af-klinthayati-ve-eserleri/), bir yorum sitesinde (ekşi sözlük) sanatçıyla ilgili bazı görüşler paylaşılmasına rağmen, soyut sanatın bu esrarengiz öncüsü hakkında hiçbir sanatsal ve bilimsel verinin bulunmaması şaşırtıcı gelmiştir. Bunun üzerine yabancı tez çalışmaları, sanatçıya dair kitaplar, sanatçını kendi not defterleri, sergi katalogları, gazete haberleri, videolar vb. incelenmiş, beklenenden çok daha fazla materyal olduğu görülmüş̧ür.

Yapılan araştırmalar sonucunda, Hilma Af Klint'in 20. yüzyılın başlarından kalma soyut resimlerinin 1987 yılına kadar kamuya sunulmamasına rağmen, Kandinsky, Mondrian ve Malevich'in ilk soyut resimlerinden daha önce yapılmış olduğu görülmüştür (Midavaine 2015, http://hilmaafklint.louisiana.dk, https://www.theartstory.org ... vb.). Günümüz sanat tarihi açısından bir dönüm noktası olacak olan bu yayın, sadece sanatın hareketli akışkanlığını ortaya koymakla kalmayacak, aynı zamanda yirminci yüzyılda soyut sanatın anlatımına da meydan okuyacak türde bir araştırmadır. Bu çalışmada önce sanat tarihi bakımından soyut sanat kavramı ele alınırken, ardından Hilma af Klint'in kısaca hayatına, sanat eğitimine ve sanatsal üretimlerine değinilerek, sanatçının kendi not defterinden de faydalanılarak yaptığı bazı resimler, içinde yaşadığı dönem açısından bu resimlerin önemi ve farklıları vurgulanarak, ilk soyut resim sanatçısı olan Hilma Af Klint'i ülkemize tanıtarak, soyut sanat anlamında önemli bir eksikliğin giderilmesi amaçlanmaktadır.

\section{Soyut Sanata Bakış}

Soyut sanat (abstract art) kavramı, yirminci yüzyılın ilk on yılı içinde doğmuş günümüze kadar uzanan bir ifade sanatıdır. Burada ifade ile kastedilen, biçimlendirme ve biçim-vermedir. Bu geniş sanat görüşü içinde, Der Blaue Reiter, Kübizm, Nonfigüratif, Konstrüktivizm ve Suprematizm, vb. gibi çeşitli anlayışlar yer almaktadır. Bu anlayışların hepsi birbirinden farklı olmasına rağmen, ortak bir noktada birleşirler: hepsi soyuttur ve soyut olma prensibine bağlıdır. Bu farklı anlayışları bir arada tutan soyutluk ilkesi, onların var-olan, tabiat ve nesneler karşısında aldıkları tavrı, nesneleri kavrayışını, yani obje yorumunu ifade etmektedir (Tunalı İ., 1970). Bir başka deyişle, "Soyutlama yönündeki çeşitli eğilimleri bünyesinde barındırmasına karşın soyut sanat, esas olarak soyutlamanın da ötesindeki bir ifade arayışının sonucudur" (Antmen, 2010:80).

Soyut kavramı, sözlük anlamı olarak (TDK Resmi Sitesi), varlı̆̆ şeklinde karşımıza çıkarken; sanatsal anlamda ise, doğada var olan gerçek nesneleri betimlemek yerine, biçimler ve renklerin, temsili olmayan veya öznel kullanımı ile yapılan sanat olarak kullanılmaktadır. Soyut sanat, özellikle estetik değerlerin form ve renklerde olduğu ve tamamen resim ya da heykelin konusundan tamamen bağımsız olduğu varsayımına dayanır (Murray P.\& L. 1997:17). Pek çok kaynakta soyut resim anlayışı Postmodernist süreç içerinde yer almakta ve ilk temsilcisi Wassily Kandinsky olarak geçmektedir. Buna göre, 1911'de ilk soyut resim Kandinsky'nin suluboyalarında görülmektedir (Gombrich, 2007:570, Antmen, age :81, Kandinsky, 2013).

Bunu Sanatın Öyküsü adlı eserinde Gombrich (2007:570) şöyle dile getirmektedir; “...Görüldü̈̆̈̈ kadarıla, bunu ilk yapan, o sıralarda Münih'te yaşayan Rus ressam Wassily Kandinsky'dir (1866-1944). Birçok Alman ressam arkadaşı gibi, gelişmenin ve bilimin ortaya çıkardiğ değerlerden hoşlanmayan Kandinsky, dünyanın, saf "ruhsallığı" temsil eden yeni bir sanat tarafindan yenilenmesini özleyen bir gizemciydi. Tutkulu ama biraz da karışık olan, Sanatta Ruhsallı Üzerine (1912) adlı kitabında saf renklerin psikolojik etkilerini vurgulamış, canlı bir kırmızının, bir boru sesi gibi bizi nasıl etkileyebildiğini belirtmiştir... Böylece "Soyut Sanat" olarak adlandırllan akımı da 
başlatmış oldu...” Antmen ise, 20. Yüzyıl Batı Sanatında Akımlar (2010:81) adlı kitabında, "Temsili gerçeklikten koparak özellikle renk öğesine ve şekillere odaklanan, böylece özünde soyut bir resimsel ifadenin yolunu açan ilk sanatçının, Rus ressam Wassily Kandinsky olduğu kabul edilmektedir..." şeklinde ilk soyut ressam hakkında açıklamada bulunmuştur. Yazar, bu konuya şu şekilde açıklık getirmiştir:

Tıpkı simgeci ressamlar gibi renkler ve sesler arasında bağ kuran, 'renk titreşimlerinin' ruhsal etkiler yarattığını düşünen Kandinsky, soyut sanatın ilk örneğini 1912 dolaylarında yapıldığı sanılan, ancak kendisinin 1910'a tarihlediği bir suluboya resimle vermiştir. Söz konusu resimden sonra sanatsal arayışlarını kuramsal bir temele oturtmak isteyen Kandinsky, 1912 yılında bir tür kişisel manifesto niteliğinde olan "Sanatta Tinsellik Üzerine” adlı kitabını yayımlamıştır. Sanatın 'içsel bir gereklilik’ten kaynaklandığına inanan Kandinsky için duyguların gerçek ifadesini bulmasında 'primitif' öğeler -örneğin içgüdüler- çok önemli bir yer tutmuş, duygunun doğrudan ifadesi sanatsal yaratının başlıca koşulu sayılmıştır. Saf sanatsal ifadeyi örnekleyen başlıca sanat türünün müzik olduğunu düşünen Kandinsky’nin sanatında belirgin bir eğilim de mistisizm olmuş; sanatın gündelik yaşamın ötesinde, sonsuz bir 'tin' in, bir evrensel ruhun algısı ve ifadesi olduğu inancı ağır basmıştır”' (Antmen, 2010:81).

Buna dayanarak sanatçının 'non-objektif' yani dış gerçeklikten soyutlanarak gerçekleştirilen resimsel ifade yerine kavramsal olarak tümüyle soyut ifadeye dayanan bir resimsel anlayıştan yana olduğu söylenebilir.

Wassily Kandinsky adı geçen kitabında (2013:39), önsezi sahibi insanların küçümsendiğini ya da anormal ve tuhaf bulunduğunu dile getirir. "Sanatçı ruhsal gücü̈le "nasıl?" sorusunun üstesinden gelebilir ve ince duygularını ortaya dökmeyi başarabilirse, sanat yitirdiği ve kendisini, gözlerini yeni yeni açan ruhsal yaşantının ruhsal gıdasina taşıyacak 'şeyin' yoluna koyulmuş olur. Bu 'şey' artık önceki dönemdeki gibi maddi ve nesnel olmayacaktır; bu, sanatçının iç hakikatidir, onsuz ne birey ne de insanlık sağglıklı olamaz. Bu şey yalnızca sanatın sezebildiği ve yalnızca onun, kendine has ifade biçimleriyle ortaya koyabildiği iç hakikattir" (Kandinsky, 2013:41).

Soyut çalışmalarıyla öne çıkan Kandinsky'nin yanı sıra Malevich ve Mondrian da bu tür resimler yapmış ve ortak bir paydada buluşmuşlardır. Bu sanatçıların ortak noktası sezgisel olanı iç hakikati yani manevi bir boyutu keşfetmiş olmalarıdır. Kandinsky, Ekspresyonizm'den uzaklaşarak ve kademeli bir şekilde görünür gerçekliği resmetmeyi denemişti. Gizli olana büyük ilgi duydu ve 1911'de Sanatta Maneviyat Üzerine adlı eserinde bu yaklaşımından bahsetmektedir. Malevich'in farklılığı ise, soyut ve son derece manevi olan imgeleri Kübizm ve Fütürizm yoluyla resmetmesiydi. Mondrian'in ise, gözünün görebileceği figüratif tasvirlerin yerini, kompozisyonunda dikey ve yatay çizgilerden oluşan bir oyuna ve ana renklerin kırmızı, sarı ve mavi renklerini beyaz ve siyahla değiştirmesiydi. O da bir teosofist olarak, görünür dünyanın ötesindeki ebedi fikirlerin tamamen manevi bir ifadesi için çabalamaktaydı. Dolayısıyla manevi araştırma, soyutlamaya yönelen birçok modernist için önemli bir unsurdur denebilir. Bu çalışmada tanıtılmak istenen Hilma af Klint'in çı̆̆ır açan resimleri ise 20. yüzyılın başlarında yani Rusya ve Avrupa'da soyut sanat başlamadan daha önce yapılmış olması bakımından önemlidir. Söz konusu ressamın yapıtlarında öne çıkan, renk ve şekillerin soyutlanmasından öte, görünür olmayanı görünür kılmasıdır. Yalnız burada dikkat çeken unsur, Hilma af Klint'in, Kandinsky, Malevich ve Mondrian'dan farklı olarak, yaratım sürecinde bir aracısı olduğu iddiasında bulunmasidir. 


\section{Hilma Af Klint Kimdir? (1862-1944)}

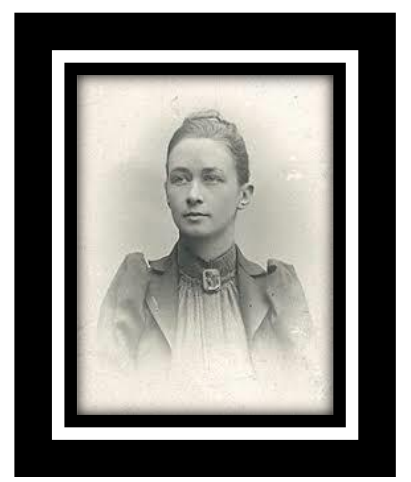

1862 İsveç doğumlu olan Hilde Af Klint, Avusturyalı ressam Gustav Klimt ve Fransız besteci Claude Debussy gibi ünlü isimlerle aynı senede dünyaya gelmiştir. İsveç Kraliyet Akademisi'nin diğer Avrupa akademilerinden farklı olarak kadın öğrenci kabul etmesiyle, af Klint, 1882'den 1887'ye kadar Stockholm'deki Kraliyet Güzel Sanatlar Akademisi'nde portre, manzara ve botanik resim alanlarında akademik sanat eğitimi almış ve mezuniyetinin ardından, dünyanın her yerinde olduğu gibi Stockholm'de de sadece erkeklerin hüküm sürdüğü sanat çevresinde kadın olduğu için kendine yer bulamamış, kariyerine bir süre kendi başına devam etmiştir.

Sanatçıyı daha iyi anlayabilme adına yaşadığı döneme şöyle bir bakılacak olursa, Hilma af Klint'in ciddi bir değişim dönemine tanıklık ettiği görülür. 19. yüzyılın sonlarında, bir dizi bilimsel gelişme radikal bir şekilde dünyaya hakim olan fikirleri değiştiriyordu. Darwin'in evrim teorileri, henüz akademik çevrelerde henüz tam olarak kabul edilmemiş olsa da, popüler kültürün hemen hemen her alanına yayılmıştı. Atom altı parçacıkların keşfi, radyoaktivite ve X-1şını, spiritualistler için, aslında, tanrı olarak görünmez bir varoluş diyarı olduğunu doğrulamıştır. Bu gelişmeler, Hilma af Klint'in düşünce ve yaşam tarzında olduğu kadar sanatına da oldukça büyük katkılar sağladı.

Bir ressam olarak, Hilma af Klint, hem fikir olarak hem de sanatsal ifadelerde kendi yolunu belirleyen yenilikçi, yaratıcı biriydi. Yeni ifade araçlarına yatkınlığı olan sanatçı hayatı boyunca yeni teknikler denediği görülür. Kıtadaki erkek meslektaşları tarafindan geliştirilen soyut sanat teorilerinden tamamen bağımsız olarak, geleneksel sanattan soyutlamaya bir anda kaymıştır. Bir ressam için alışılmadık bir şekilde, birkaç kez boyama şeklini kökten değiştirdi. Geleneksel bir manzara ve portre ressamı olarak başlayan ressamın,1906'da soyut resme geçtiği görülür (Klint J., Ersman H. 2018).

Hilma af Klint, önce küçük kardeşinin on yaşında ölmesiyle derinden etkilendi, ardından babasının ölümü ve sonrasında annesinin körlüğünün kötüye gitmesi gibi sebeplerden kendini maneviyata verdi (Midavaine B. ;2015). 19. yüzyılda Amerika ve İngiltere'de popülerleşen Spiritualizm (Ruhçuluk) akımının İskandinavya'da da yayılmasıyla metafizikle ilgilenmeye başladı. 1879'da, on yedi yaşındayken, Spiritizm seanslarına katıldı (ölülerle bağlantı kurmaya çalışıyordu) ve Spiritist (ruhlara inan kimse) Edebiyat Derneği'ne üye oldu. Ancak Hilma af Klint daha sonra Spiritizm'in, insanların henüz hazır olmadıkları, önceden bilgi almaları için yalnızca bir kısa yol olduğu düşüncesiyle, 1882'nin başlarında Spiritist hareketten ayrıldı (Klint J., Ersman H. 2018).

Klint, 1896 yılında dört kadın ressamla bir araya gelerek, "The Five" (De Fem) adını verdikleri bir sanat grubunu kurdu, "Beş" olarak da adlandırılan gruba "Cuma Grubu" da demekteydiler. Çünkü her cuma, dualarla başlayan, Yeni Ahit çalışmaları ve meditasyon çalışmaları ile başlayan ve ardından manevi toplantılar için bir araya geldiler (www.hilmaafklint.se). Bu grupta transa geçerek resim yapmayı deneyimlediler. Söz konusu bu grup, daha Sürrealizm doğmadan önce seanslar şeklinde, otomatik yazma (Bkz. Resim 1) ve çizme denemeleri yaptılar. Bu Seans sırasında notlar tutarak 
gözlemlerini kayıt altına aldılar. Dolayısıyla Sürrealizmin simgesi olan bilinçdışı üretimi (otomatizm) sanatla ilk defa birleştiren sanatçının Hilma af Klint ve birlikte çalıştığı The Five grubu olduğu açıktır (Serpentine Galleries, 3th March-15th May 2016, Klint J., Ersman H. 2018).

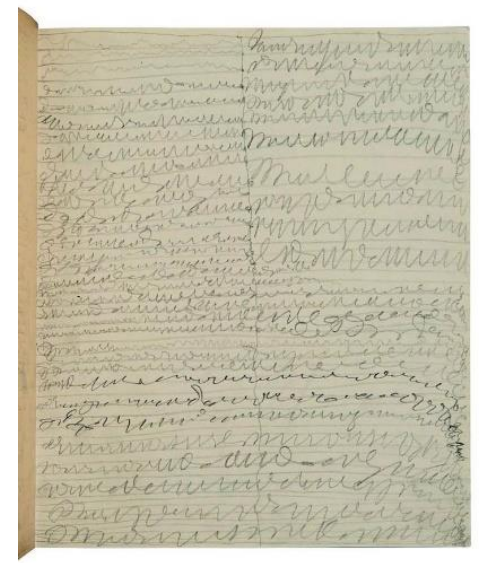

Resim 1- Otomatik Yazı, The Five, 1896.

Maddi ve manevi dünyalar arasında bir uyum yakalama niyetinde olan sanatçı, 1904'te Tapınak için Resimler'i ortaya çıkarmak için ilahi bir varlıktan ilham aldığını dile getirir; iyi ve kötü, erkek ve kadın, din ve bilim gibi (Klint J., Ersman H. 2018). Bu öğeleri, eserlerinde renk, kompozisyon ve sembollerin kullanımıyla ve soyutlama ile hiyerarşiden yoksun bir şekilde resme yansıtır. "Bir insan gerçeğe hizmet etmiyorsa, hayat bir saçmalıktır" diyerek de gerçeği olduğu gibi aktardığına vurgu yapar (www.theartstory.org). O zamana dönecek olursak, sanayileşme ile birlikte insanların ülkelerinden kaçıp kasabalara yerleştiği, şehir ile sosyal ağlarını kestiği görülür. Doğa bilimlerinde öne çıkan bu önemli keşifler, insanların beş duyumuzla algılayamayacağımız yönlerin olduğunu fark etmelerini sağladı. Bu değişim ve belirsizlik ortamında, çeşitli dini hareketler mantar gibi ortaya çıkmaktaydı. Toplumun her seviyesinden insanlar, tutunmak için yeni bir şey aramaktaydılar. $\mathrm{Bu}$ dönemde Theosophy de kuvvetli bir ilham kaynağıydı. Klint de, zamanındaki ruhsallık, Teosofi ve daha sonra Antropoloji gibi bir dizi ruhsal araştırma ve deneysel akımın da etkisiyle, 1906'da yani 44 yaşındayken Tapınak için Resim (Bkz. Resim 2) adlı ilk soyut resim serisine başladı. Bu da Hilma af Klint'in Kandinsky'den beş yıl önce ilk soyut resimi yapmış olduğunu göstermektedir (Klint J., Ersman H. 2018).

Af Klint, bu çalışma öncesi manevi bakımdan arınmak için yaklaşık 10 ay boyunca, vejetaryen diyeti uyguladı ve bu şekilde kendini disipline ederek sanatsal görevine hazırlandı. Bu serileri yaparken 1908'de birkaç dinlenme arası vererek (ruh rehberlerinin isteği ile), 1908'de, 193 eserden oluşan tuval ve kâğıt üzerine anıtsal bir döngüde ilk 111 parçalık resimlerini tamamladı. Kullandığı simgesel görsel dili için bir sözlük görevi de görmesi düşüncesiyle, yaşadığı ruhsal durumu ve ressamlık süreci boyunca yaşadığı gelişmeleri saplantılı bir şekilde ayrıntılı olarak defterlere kaydetti. 1915'te doruğa ulaşan, her biri altı diziden oluşan bu serilere ait 193 eser üretti (www.artsy.net). Bu yoğun yaratıcı dönemde resimlerini, Amaliel, Ananda, Clemens, Esther, Georg ve Gregor isimlerindeki 'daha yüksek bir gǚç' tarafından yönlendirilen bir 'kuvvet' sayesinde yaptığından bahsetmektedir. 1903'te söz konusu bu ruhlardan George ve Ananda resimlerle dolu bir tapınağa ihtiyaç duyulduğunu açıkladı (Schjeldahl P., 22.10.1018). Sanatçı sadece zihninin gözüne çarpan şeyi kaydetmekte ve insanlık ve kozmos arasındaki ilişkiyi ve insanın daha yüksek bir anlayışa doğru olan yolculuğu ile gelişimini tasvir etmekle görevlendirildiğini şu sözüyle belirtmektedir: "Resimler doğrudan içimden, ön çizimler olmadan ve büyük bir güçle boyandl. Resimlerin neyi göstermesi gerektiği hakkında hiçbir fikrim yoktu; yine de tek bir firça darbesini değiştirmeden huzlı ve emin bir şekilde çalıştım” (https://www.theartstory.org). 
Sanatçının bu seriyi yaparken amacının, insanlık ve kozmos arasındaki ilişkiyi ve insanın daha yüksek bir anlayışa doğru olan yolculuğu ve gelişimi tasvir etmek olduğu söylenebilir.

Hilma af Klint, her şeyin doğal olarak gerçekliğinin yanı sıra manevi bakımdan fiziksel bir vücuda sahip olduğuna da inanıyordu. Bu inançla, 1916-1920 tarihleri arasındaki döneminde dünyayı, evreni, yaşamsal konuları, maddi konuları ve aralarındaki dengeyi analiz etti. Bazı resimlerinde, bu analizleri yaparken tasarladığ 1 maddenin hangi manevi seviyeye ait olduğunu gösteren küçük bir diyagramlara da yer vermiştir. Bunu yaparken de bazı sembollerden faydalanmıştır.

\section{Semboller}

Hilma af Klint resimlerinde sembolik olarak pek çok imge kullanmaktadır, bunların yanı sıra harfler ve kelimeler de resimlerinin birer elemanıdır. Bu semboller, başka bir boyuta açılan kapılar gibidir. Hilma af Klint'e göre, bütün çalışmalarının amacı, aldığı mesajları iletmek ve varoluşsal sorunlara 1 ş1k tutmaktır.

Hilma af Klint'in eserlerinde yer alan sembol ve harfleri kesin terimlere çevirmek pek mümkün olmasa da, tüm resimleriyle ilişkisi olduğu düşünülmektedir. Anlaşılır olması bakımından sanatçı, Semboller adlı not defterinde (Notes on Letters and Words pertaining to Works by Hilma af Klint), çeşitli işaretlerin karmaşık anlamlarıyla ilgili bazı açıklamalarda bulunmuştur. İşte buna göre birkaç genel açıklama şu şekildedir:

Salyangoz veya spiral, gelişimi yani evrimi temsil eder. Kuşgözü ve kanca, mavi ve sarı, zambak ve gül sırasıyla kadınlığı ve erkekliği temsil eder. ' $W$ ' madde anlamına gelirken, ' $U$ ' ruh anlamına gelir. İki daire üst üste bindiğinde ortaya çıkan badem şekline vesica piscis denir ve birlik ve tamamlanmaya doğru gelişme için eski bir simgedir. Kuğu birçok mitolojide ve dinlerde etiği temsil eder ve simya geleneğinde bitirme anlamına gelir. Hıristiyanlıkta, güvercin kutsal ruhu ve sevgiyi temsil etmektedir (www.artblart.com).

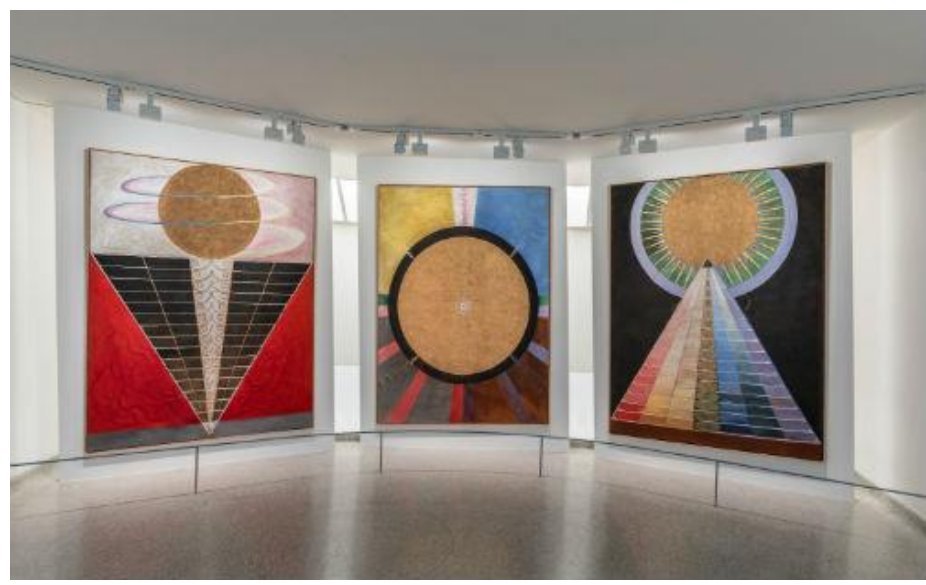

Resim 2- Tapınak için Resimler, Tuval üzerine yağlıboya, 1906

Sanatçının bu serisi için Tapınak için Resimler ismi seçmesi de önemlidir. Sanatçı, bu resimleri izleyicilerin ölümlü ve dünyevi alemlerin ötesine geçmelerinde kılavuz olması için tasarlandığını ileri sürüyor. Af Klint burada, herhangi bir dine atıfta bulunmak yerine (bu nedenle, kilise, sinagog veya cami kelimesini kullanmaz), karşıtlar birliği aracılığıyla denge kurmaya adanmış evrensel bir ibadet yeri olan 'tapınağı' inşa etmeye çalışır... 1915 itibariyle, bu serisinin ardından, Klint 'ilahi rehberliğinin' sona erdiğini belirtir ve sonrasında sanatçının resim yapısına, büyüklük ve ortama göre yaklaşımının değiştiği görülür (www.theartstory.org). 


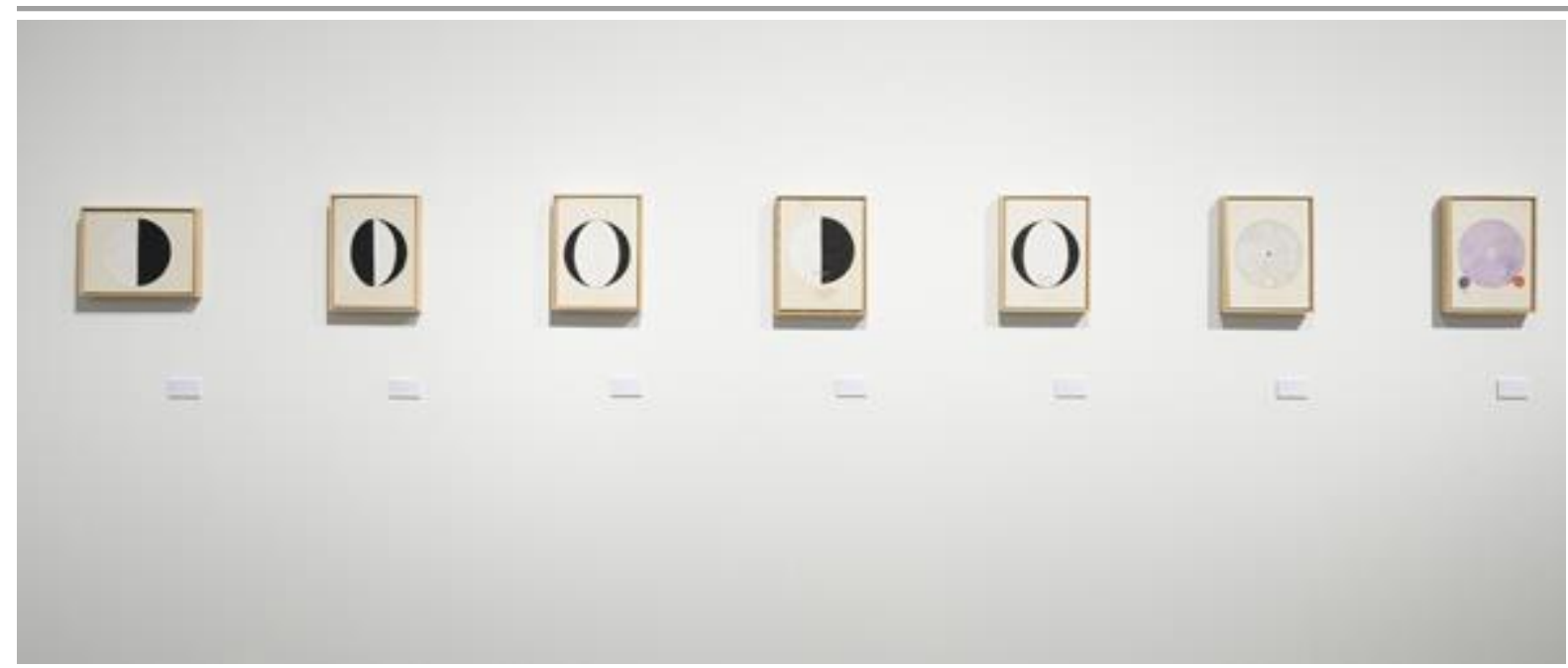

Resim 3- The Mahatmas Present Standing Point, Series II, Tuval üzerine yağliboya, 1920

1920 'de annesinin ölümüyle birlikte ağırlıklı olarak dünya dinlerini inceleyen Klint'in sanat hayatında bunlar da yer almaktadır. Kazimir Malevich'in Suprematist tuvalleriyle güçlü bir benzerliği olan resimler yaparak (Bkz. Resim 3), sanatçı Budizm'e odaklanır, ancak Hıristiyanlık, Yahudilik ve İslam için de resimler yapmıştır. Diziye, bir siyah yarı daireye ve bir beyaza bölünmüş bir daire ile başlar. Oradan, siyah ve beyaz renkli alanlar, Klint'in manevi bakış açısına göre değişir.

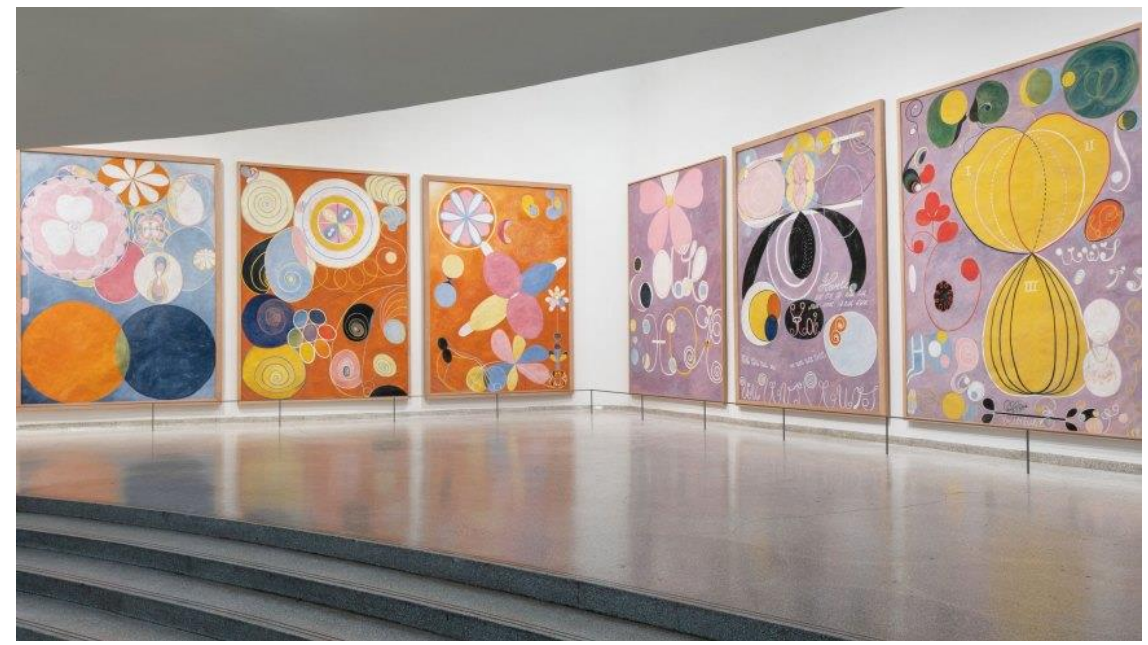

Resim 4- Hilma Af Klint Exhibition At The Guggenheim Museum, 12 Ekim 2018-23 Nisan 2019

Sanatçı sonrasında, çiçek ve ağaçların bilimsel inceliklerini araştırmaya dayalı oldukça yaratıcı çalışmalar yapmıştır. Giderek artan geometrik biçimsel dil 1920'lerin son dönemlerinde Hilma af Klint'in tarzını değiştirir ve keşiflerini daha akıcı bir karaktere sahip suluboyalarla sürdürür. Güney İsveç'teki bir sahil kenti olan Helsingborg'a taşınmasının ardından 1921-1930 yılları arasında İsviçre'deki Goetheanum'u (Dünya Antropoloji Hareketi Merkezi) ziyaret eder, Antropoloji topluluğuna katılır, Rudolf Steiner'la tanışır ve onun teorilerinin etkisinde kalır. Bu süre zarfinda Hilma af Klint, kendi miras bırakacağı çalışmalarının, resimlerinin kataloglanması ve fotoğraflanması, uygulamalarının belgelenmesi, dergilerinde ve eskiz defterlerinde yazması ve önceki keşiflerin gözden geçirilmesi ile ilgili düzenlemeler yapar. 
Hilma af Klint yaşamı boyunca 125 adet günlük yazmış ve bu not defterleri de, sanatçıyı tanıma ve sanatını anlamlandırabilme konusunda günümüze 1şı tutmuştur. Bu notları aynı zamanda kitap olarak da yayımlanmıştır (Hilma af Klint: Notes and Methods, 2018). Devasa büyüklükteki tuvalleri ile dikkat çeken sanatçının, çoğunlukla mistik konulara yönelmiş olduğu, kurduğu spritüel bağı oldukça etkili bir resim diliyle otomatizme dayalı bir şekilde aktardığı görülmektedir. İncelenen kaynaklarda (Leon E., 2018; Serpentine Galleries, 2016, Klint J., Ersman H. 2018 ...vb.), sanatçının bu günlüklerinde tablolarını trans halindeyken koruyucu meleğinin kendisine çizdirdiğine dair ifadeler vardır (Bkz. Resim 4). Söylendiğine göre, koruyucu meleği Hilde'den işlerini sergilememesini istemiştir. Hilde'nın meleğine verdiği söz bir mit midir bilinmez, ama her yerde bu başarısını afişe edecek özgüveninin olmaması ve sanat çevresi tarafindan bir köşeye itilmişlik düşüncesi ile "Toplum beni anlamaz" diye 1000'e yakın soyut eserini bir köşeye saklaması o dönemde de cinsiyet normlarının nasıl olduğu konusunda ipucu vermektedir. Ona meleği işlerinin ancak öldükten yirmi yıl sonra sergilenebileceğini söylemiştir. İroniktir ki, açığa çıkması planlanan bu dönem, soyut resmin modern sanat tarihinde zirveye taşındığ 1 1960'lara denk gelmektedir. 80'li yaşlarındayken kuzeni Hedvig'le yaşamaya başlayan af Klint, tüm eser ve defterlerini ölümünün yirmi yıl sonrasında halka açıklanmasını şartıyla kuzenine emanet etti. Ancak buna rağmen eserleri ancak 40 yıl sonrasında gün yüzüne çıkabilmiştir (Klint J., Ersman H. 2018). 1944 yılında Kandinsky, Munch ve Mondrian ile aynı sene ölen Hilma af Klint'in soyut çalışmalarından hiç biri ölümüne kadar halka gösterilmemiştir.
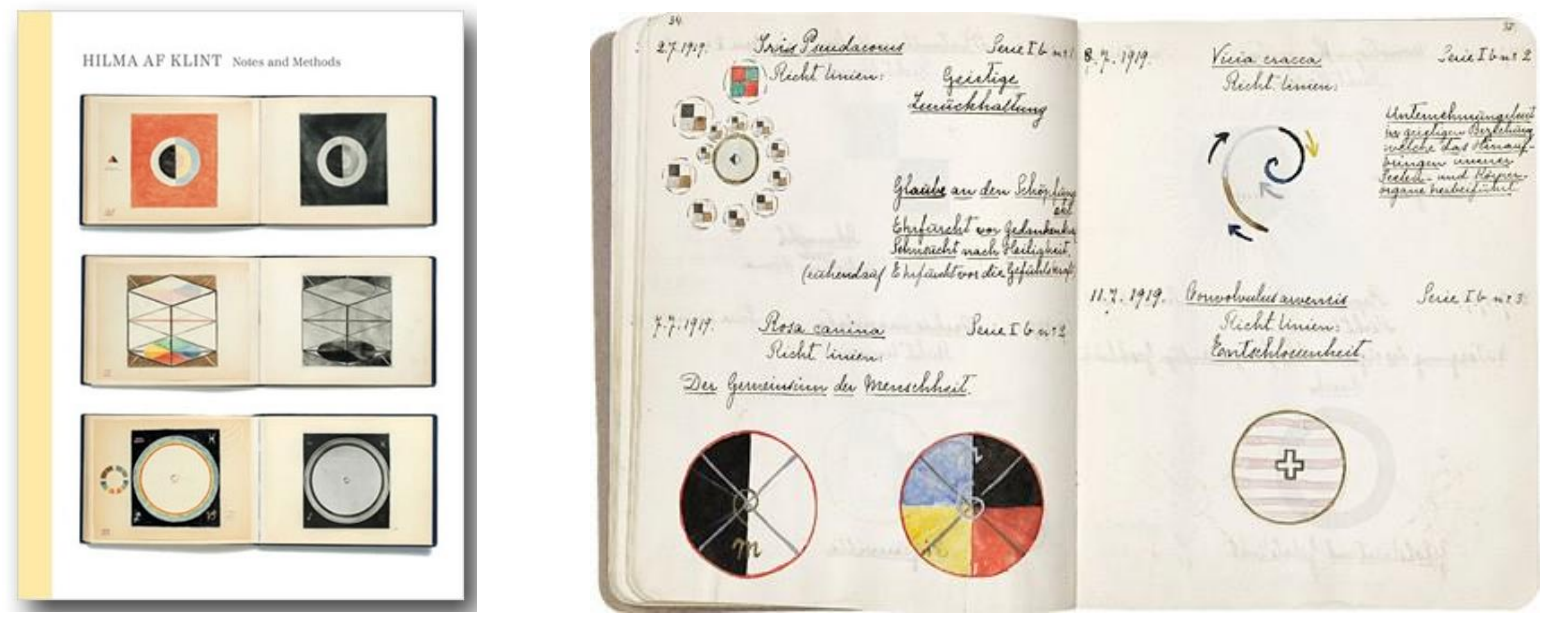

Resim 5- Hilma af Klint, Sanatçının Not Defteri, Mosses and Lichen, July 2 1919, Moderna Museet, Albin Dahlström

Sanatçının ölümünün ardından ilk kez 1986'da gün yüzüne çıkan resimleri Los Angeles Kontluk Müzesi'nde “Soyut Resim Sanatında Spiritualizm” (The Spritual in Art Abstract Paintings 1890-1985) başlığıyla halka sunulmuş ve ardından Avrupa ve Latin Amerika'da da sergilenmiştir. Günümüze kadar sanatçının eserleri kişisel ve karma olarak dünyanın pek çok galeri ve müzesinde sanatseverlere sunulmuştur. ${ }^{1}$ Klint'in eserlerinin tamamı ve sanatçının yazdığ 1 defterleri (Bkz. Resim 5). İsveç'de

\footnotetext{
${ }^{1}$ Hilma Af Klint'in Kisisel Sergileri;

1986 - 20 yıl. Af Klint'in soyut eserlerinin ilk halka açık sergisi, County Sanat Müzesi, Los Angeles; 2005-2006 Çizim Merkezi, New York; 2005-2006 Santa Monica Sanat Müzesi, Kaliforniya; 2005-2006 İrlanda Modern Sanat Müzesi, Dublin; 2006 - Camden Sanat Merkezi, Londra. 2008 - Bochum Kunstmuseum, Almanya; 2008 - Moderna Museet, Stockholm; 2008 - Centre Pompidou, Paris; 2008 - Centre Culturel Suédois, Paris; 2009 - Haus der Kunst, Münih; 2010 - Müze Moderne Kunst, Arnhem; 2013 - 55th International Art Biennale Venice 2013, Venedik; 2013 - Soyutlamanın Öncüleri Sergisi, Moderna Museet, Stockholm; 2013 - Hamburger Bahnhof, Berlin; 2013-2014 Museo Picasso, Malaga;2014 - Louisiana Modern Sanat Müzesi, Humlebæk; 2015 - Henie-Onstad Sanat Merkezi, Oslo; 2015-2016 Henie Onstad Art Center, Oslo; 2016-2016 Serpentine Gallery, London; 2017 - Irish Museum Of Modern Art, Ireland; 2018-2019 - Solomon R. Guggenheim Museum, New York.
} 
kurulan Hilma Af Klint Vakfına (The Hilma af Klint Foundation) bağışlanmıştır... Hilma af Klint Vakfı, Ocak 1972'de Erik af Klint tarafindan kurulan kar amacı gütmeyen bir organizasyondur. Vakfın amacı, Hilma af Klint'in sanatsal mirasını korumak ve yönetmenin yanı sıra, sergiler, internet ve diğer medya aracılığıyla halka sunulmasını sağlamaktır. Vakıf, Hilma af Klint ve eserleri ile ilgili akademik araştırmaları, talep edilen her türlü bilgiyi cömertçe sağlayarak ve eserlere dijitalleştirilmiş formlarında erişerek teşvik ederek desteklemektedir. Vakıf, sanatçı Hilma af Klint'in soyut çalışmalarına, resimlerine ve Olof Sundström 1945 tarafından oluşturulan sicile göre numaralandırılarak çeşitli eserleri (eskizler, eskiz defterleri, defterler ve diğer önemli malzemeler) saklamaktadır (www.hilmaafklint.se, 20 September 2018).

2013 y1lında Hilma Af Klint'in 55. Venedik Bienali'ne seçilen eserleri (Bkz. Resim 6) Stockholm, Berlin, gibi farklı noktalarda da sergilenmiştir (Klint J., Ersman H.; 2018:6). Bu bienal çerçevesinde Ann-Sofi Noring "Hilma af Klint'in Mirası" (The Legacy of Hilma af Klint), adlı bir kitap hazırland1 ve burada Klint'in 1919'daki defterlerinden (Flowers, Mosses, Lichens) alınan çizimler yayımlandı. Sanatçının orijinal defterine sadık kalınarak hazırlanan bu kitapta, her bitkinin manevi özünü ve oyundaki manevi güçleri temsil eden mimetik olmayan çizimlere yer verildi (Müller I., Widoff J.; 2013).

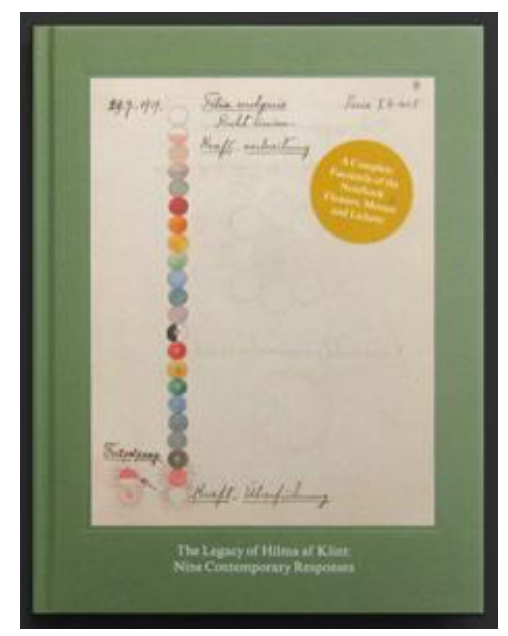

Resim 6- Hilma af Klint, The Dove, No. 13, 1915; 55. Venedik Bienali, 2013.

Ortaya çıktığı ilk tarihten itibaren ilgi odağı olan ve başlangıçta sanat tarihinde akademik tartışmalara ve bilimsel incelemelere sebep olan bu sanatçı, zaman içinde hak ettiği konuma gelmiş ve sıklıkla güncel sanat haberlerinde, sanat kitaplarında, müzelerde, akademik çalışmalarda vb. kendini göstermiştir. 3-15 Mayıs 2016 tarihleri arasında çeşitli üniversitelerden katılan profesör ve bazı galerilerin sanat yönetmenleri eşliğinde bir vakıf (Axel ve Margaret Ax: son Johnson Foundation) tarafından İsveçli öncü sanatçı Hilma Af Klint üzerine, Serpentine Galeri'de "Görmek İnanmaktır, Hilma Af Klint'in Bugünkü Önemi" (Seeing Is Believing On Hilma Af Klint's Importance Today) konulu üç haftalık bir sempozyum ve eş süremsel olarak sergiler düzenlenmiştir. Stockholm, Berlin ve Oslo'da düzenlenen bu sempozyumlarda sanatçının düşsel çalışmaları, yaşadığı çağ içerisinde değerlendirilerek günümüz sanat tarihindeki yeri ve önemi üzerine paylaşımlarda bulunulmuştur. Sanatçının resimlerinde kullandığı imgeler, ruhsal dünyası, botanikle olan bağı, kullandığı renkler ve kompozisyonlarındaki soyutlama tekniği ile ilgili bildiriler sunulmuştur. Ardından bu bildiriler de, "Görünürü Görme Sanatı" (Hilma Af Klint- The Art of Seeing the Visible) adı altında bir kitapta (Bkz. Resim 7) toparlanmıştır (Axel ve Margaret Ax: son Johnson Foundation, 9 Mayıs 2016).

* Detaylı bilgi için bkz. https://www.hilmaafklint.se/exhibitions-eng/\#Past\%20Exhibitions 


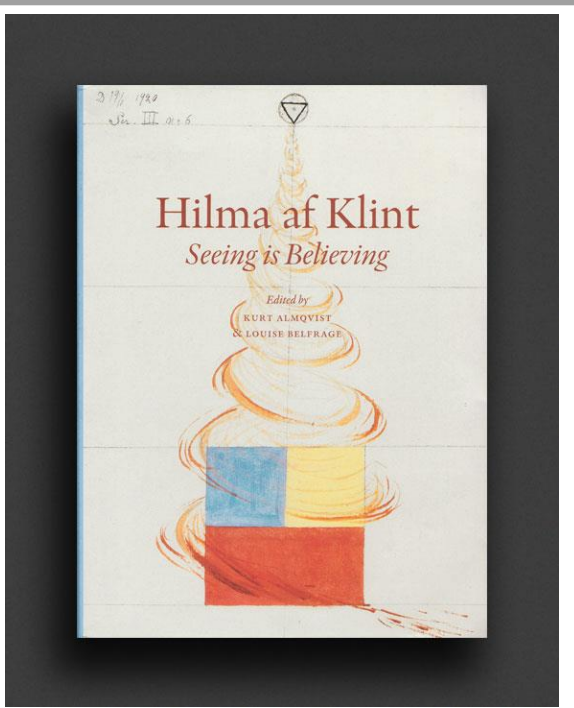

Resim 7- "Görünürü Görme Sanatı"(Hilma Af Klint- The Art of Seeing the Visible), Axel ve Margaret Ax: son Johnson Foundation, 9 Mayıs 2016.

\section{Sonuç}

Postmodern süreç içerisinde görünenin ruhsal boyutunu yani görünmeyeni resmetmek isteyen pek çok ressam olmuştur. Yerel kaynaklarda soyut bir anlatım tarzı olarak ifade edilen bu yolu açan ilk sanatçının, Rus ressam Wassily Kandinsky olduğu kabul edilir. Kandinsky'nin ilk soyut resmini 1911 'de yaptığı bilmektedir. Ancak 1987'den sonra yabancı kaynaklarda onun yerine bambaşka bir isim ön plana çıkmaktadır. Yapılan araştırma ve incelemelerin sonrasında, İsveçli sanatçı Hilma Af Klint'in ondan beș sene önce (1906) ilk soyut resmi yaptı̆̆ görülmüștür. Söz konusu sanatçı, dört arkadaşıyla kurdukları 'The Five' adlı grupla ruhlarla bağlantı kurup, görüşmelerini otomatizm yoluyla defterlere kaydetmişlerdir. Bu yönüyle Sürrealistlerden önce de otomatik yazı denemeleri yaptıklarını söylenebilir.

Hilma af Klint sanat hayatı boyunca, Avrupa'daki Avangart hareket hakkında çok az bir bilgi birikimiyle ve yalıtılmış bir şekilde çalışmıştır. Klint, 1000'in üzerinde soyut resim yapmış, tema olarak, insanlık ve kozmos arasındaki ilişkiyi, insanlığın gelişim veya evrimini, kadın ve erkek, göksel ve yeraltı dünyası, iyi ve kötü, barış ve savaş gibi karşıtlıkları denge içerisinde resmetmiştir. Sanatçı, bu resimlerinde geometrik şekilleri ve sembolleri süslemelerle birleştirmiştir. Resimlerinde kullandığı çok yönlü imgeler ile sanatçı, mikro kozmos ve makro kozmosun birbirlerini yansıtan varoluşun farklı boyutlarına dair içgörü vermeye çalışmaktadır. Devasa büyüklükteki tuvalleri ile dikkat çeken sanatçının, çoğunlukla mistik konulara yönelmiş olduğu, maneviyattan beslenerek oldukça etkili bir resim diliyle otomatizme dayalı bir şekilde aktardığı söylenebilir. Wassily Kandinsky gibi, daha önce soyut sanatın başkahramanları olarak kabul edilen Piet Mondrian ve Kazimir Malevich gibi, Klint de, tinsellik, teosofya ve daha sonra antropoloji gibi çağdaş manevi hareketlerden etkilenmiş, ancak diğerlerinin ilahi bir rehberi yokken, Hilma af Klint'in eserlerinin ruhsal bir rehbere dayandığını görmekteyiz.

Sanatçı eskizlerini, düşüncelerini ve spritüal deneyimlerini 125 adet günlükte toparlamıştır. $\mathrm{Bu}$ günlüklerde sadece zihninin gözüne çarpan şeyi kaydetmez aynı zamanda insanlık ve kozmos arasındaki ilişkiyi ve insanın daha yüksek bir anlayışa doğru olan yolculuğu ile gelişimini tasvir etmekle görevlendirildiğini de belirtmektedir. Günlüklerin bir bölümünde, ölümünden 20 yıl sonra eserlerinin nasıl bir atmosferde ve hangi düzen içerisinde izleyiciye sunulması gerektiği hakkında da bilgiler yer almaktadır. İroniktir ki, açığa çıkması planlanan bu dönem, soyut resmin modern sanat tarihinde zirveye 
taşındığ 1960'lara denk gelmektedir. Sanatçının bu vasiyetine rağmen eserleri ancak 40 yıl sonra halka sunulmuştur. Şu an bu eserleri adına açılan bir vakfın himayesindedir. ${ }^{2}$

Sonuçta, soyut resmin öncüsünün Kandinsky değil de Klint olduğunu söylemek yanlış olmayacaktır. Çünkü Klint, Kandinsky'den önce kurduğu spritüal bağ ile 'Görünmez'i göstererek bir anlamda insanlığa ilahi mesajlar ileterek, görmemiz ve üzerinde düşünmemiz için, devasa tuvaller üzerine fiziksel formlarda felsefi fikirler ve manevi kavramlar sunmuştur. Sanatçı hakkında bugüne kadar pek çok kongre yapılmış, kitaplar yazılmış, akademik çalışmalar yapılmıştır. Bunlar da onun ne denli güçlü bir sanatçı olduğunu açıkça göstermektedir.

\section{KAYNAKÇA}

Antmen, A., Sanatçılardan Yazılar ve Açıklamalarla 20. Yüzyıl Batı Sanatında Akımlar, 3. Bask1, Sel Yayınc1lık, İstanbul, 2010.

Axel ve Margaret Ax: son Johnson Foundation together with the Serpentine Galleries, Seeing Is Believing On Hilma Af Klint's Importance Today, An International Seminar, at the GoetheInstitut, 9th May 2016.

Bauduin T., Birnbaum D., Fer B., Greene V., Horowitz D. M., Kollnitz A., Molesworth H., Voss J.; Edited with text by Tracey Bashkoff, Hilma af Klint: Paintings for the Future, Guggenheim Museum, 10/23/2018

Birnbaum D., Fer B., Joseph B., Lomas D., Obrist H. U.; Editors : Kurt Almqvist and Louise Belfrage, Hilma af Klint - Seeing is Believing, Axel and Margaret Ax:son Johnsons Foundation, 2017.

Gombrich E. H., Çev. Erduran E. Ö., Sanatın Öyküsü, Remzi Kitabevi, Çin, 2007.

Kandinsky W., Çev. Ekinci G., Sanatta Ruhsallı Üzerine, 645 Yayın, İstanbul, 2013.

Klint H. , Notes and Methods, The University of Chicago Press, United States, 2018.

Klint J., Ersman H, The Hilma af Klint Foundation, www.hilmaafklint.se, 20 September 2018.

Leon V. E., Analyzing the Crisis of Hilma af Klint: The Digital and Analog Analysis of Spirituality, Abstraction, and Art, Department of Art, Art History \& Visual Studies Duke University, Thesis submitted in partial fulfillment of the requirements for the degree of Master of Arts in the Department of Art, Art History \& Visual Studies in the Graduate School of Duke University 2018.

Midavaine B., Htlma Af Klint: The Medium Of Abstraction, A thesis submitted in partial fulfillment of the requirements for the degree of Master of Science History of Art and Design School of Liberal Arts and Sciences Pratt Institute, February 2015.

Müller-Westermann I.; Widoff J., A Pioneer of Abstraction Levisse, https://arthist.net/reviews/7393/mode=exhibitions

Peyton-Jones J., Obrist H; Text by Daniel Birnbaum, Jennifer Higgie, Julia Voss. , Hilma af Klint: Painting the Unseen, KOENIG BOOKS, 6/28/2016.

Tunalı, İ . (2013). Soyut Sanatta Realite Kavrayışı. Felsefe Arkivi, 0 (17), . Retrieved from http://dergipark.gov.tr/iufad/issue/1319/15564, Erişim Tarihi:15.05.2019, 14:00

\footnotetext{
${ }^{2}$ Sanatçının tüm eser ve defterleri Stockholm'de Klint adına kurulan vakıf himayesinde sanatseverlere sunulmakta olmadır.yanı sıra da uluslararası boyutta yapılmış ve yapılacak olan sergi ve etkinlikler paylaşılmaktadır. Bununla birlikte bu vakfın resmi web sitesinde Hilma af Klint'in hayatı, eserleri, sergileri, defterleri, onunla ilgili yazılmış olan kitaplar ve hakkında yazılan akademik çalışmalara da yer verilmektedir (www.hilmaafklint.se).
} 
http://www.arttv.com.tr/yazi/isigin-ve-umudun-ressami-hilma-af-klint-yazan-selen-sarioglu, 19.12.2018; Erişim Tarihi: 10.03.2019, 11:50

https://www.hilmaafklint.se/hilma-af-klint-foundation/ Erişim Tarihi:15.05.2019, 10:00

https://tr.euronews.com/2013/06/28/hilma-af-klint-in-sir-gibi-sakladigi-tablolari-berlin-de

Tarihi: 26.02.2019, 15:30)

http://www.5harfliler.com, Sever, H. L., 09.12.2013, Erişim Tarihi:15.05.2019, 11:00

https://www.bilgiustam.com/hilma-af-klint-hayati-ve-eserleri/ Erişim Tarihi:12.05.2019, 11:20

http://en.louisiana.dk/exhibition/hilma-af-klint, Erişim Tarihi:05.03.2019, 13:00

https://www.theartstory.org/artist-af-klint-hilma-life-and-legacy.htm\#biography_header, Erişim Tarihi:05.03.2019, 13:30

http://www.tdk.gov.tr/index.php?option=com_gts\&kelime=SOYUT, Erişim Tarihi:05.03.2019, 15:00

https://www.theartstory.org/artist-af-klint-hilma-life-and-legacy.htm\#biography_header, Erişim Tarihi:05.03.2019, 16:30

https://www.artsy.net/article/artsy-editorial-swedish-mystic-hilma-af-klint-invented-abstract-art, Erişim Tarihi:05.04.2019, 11:00

https://www.theparisreview.org/blog/2018/10/12/the-first-abstract-painter-was-a-woman/ Erişim Tarihi:06.04.2019, 15:40

https://www.newyorker.com/magazine/2018/10/22/hilma-af-klints-visionary-paintings

Peter Schjeldahl, 22.10.2018. Erişim tarihi:27.03.2019, 17:03

https://www.serpentinegalleries.org/sites/default/files/pressreleases/hilma_af_klint_press_release_final.pdf, Erișim Tarihi:06.04.2019, 15:50

https://www.serpentinegalleries.org/sites/default/files/pressreleases/hilma_af_klint_press_release_final.pdf, Erişim Tarihi:06.04.2019, 15:55

https://www.hilmaafklint.se/invisible-made-visible-en/ Erişim Tarihi:07.03.2019, 13:40

http://www.art-agenda.com/dossiers/tree-of-life/ Erişim Tarihi:06.04.2019, 15:40

https://worldfoodbooks.com/item/hilma-af-klint-2, Erişim Tarihi:06.04.2019, 12:40

http://hilmaafklinten.louisiana.dk timeline, Erişim Tarihi:08.04.2019, 10:20

http://hilmaafklinten.louisiana.dk/images/HILMAAFKLINTTIDSLINIE.pdf\#zoom=800, Erişim Tarihi:08.04.2019, 10:25

https://artblart.com/tag/hilma-af-klint-the-ten-largest/ Erişim Tarihi:04.04.2019, 13:20

http://www.lenbachhaus.de/blog/hilma-af-klint-painted-for-the-future-and-the-future-is-now/ BY JOHAN AF KLINT AND HEDVIG ERSMAN. "Hilma Af Klint Painted For The Future And The Future Is Now" Erişim Tarihi:09.03.2019, 11:20

http://sahriye.blogspot.com/search?updated-max=2017-05-25T23:09:00\%2B03:00\&maxresults=7\&reverse-paginate=true, Erişim Tarihi:05.03.2019, 16:50

"Hilma Af Klint" - Gertrud Sandqvist @ Summer Academy 2010 https://www.youtube.com/watch?v=dbKcV... Erişim Tarihi:12.04.2019, 14:20

Daniel Birnbaum. The Work of Hilma af Klint. 2016 https://www.youtube.com/watch? $\mathrm{v}=\mathrm{CdC5O}$, Erişim Tarihi:08.04.2019, 10:45

http://hilmaafklinten.louisiana.dk/images/HILMAAFKLINTTIDSLINIE.pdf\#zoom=800, Erişim Tarihi:08.04.2019, 16:20 